Original Article

\title{
Effect of Eight Weelks of Aerobic and Aerobic-Resistance Trainings after Coronary Artery Bypass Grafting on Expression of CCL2 and CCL5 in Middle-Aged Men
}

Najmatol Sabah Alavizadeh $(\mathrm{PhD})$,Department of physical Education,faculty of Education and psychology zahedan branch,Islamic Azad university,zahedan,Iran

Amir Rashidlamir iD

(PhD) Department of Sports Physiology, Faculty of Sports Sciences, Ferdowsi University of Mashhad, Mashhad, Iran

Seyed Mahmoud Hejazi ID

(PhD) Department of Physical Education, Khayyam University, Mashhad, Iran

Corresponding author: Najmatolsabah

Alavizadeh

Email:Alavizade80@yahoo.com

Tel: +989153438509

Address: Department of Sports Physiology, Zahedan branch, Islamic Azad University,

Received: $2020 / 05 / 18$

Revised: $2020 / 05 / 18$

Accepted: $2020 / 07 / 30$

\section{(c) (i) \&}

This work is licensed under a Creative Commons Attribution 4.0 License.

DOI: $10.29252 / \mathrm{mlj} .15 .1 .19$

\begin{abstract}
Background and objectives: Chemokines are a group of proteins involved in both innate and adaptive immunity with a significant role on homeostasis and immune system development. The present study aimed to evaluate effects of eight weeks of cardiopulmonary rehabilitation exercise after coronary artery bypass surgery on expression of chemokines CCL2 and CCL5 in peripheral blood mononuclear cells of middle-aged men.

Methods: The study was performed on 45 middle-aged men that had undergone coronary artery bypass surgery. The subjects were randomly divided into three groups of control $(n=15)$, aerobic exercise $(n=15)$ and combined aerobicresistance exercise $(n=15)$. The trainings were performed three times a week for eight weeks at $60-75 \%$ of target heart rate. Fasting blood samples were collected 24 hours before the first training session and 48 hours after the last training session. Lymphocytes were separated by centrifugation. Change in gene expression was investigated by real time-PCR. Data were analyzed in SPSS (version 16) using one-way analysis of variance and Tukey's post hoc test.

Results: The eight week exercise training significantly decreased expression of CCL2 compared to the control group.

Conclusion: Rehabilitation exercise can be an effective way to prevent, control or reduce atherosclerosis by lowering expression of CCL2 and CCL5.

Keywords: Cardiac Rehabilitation, Gene Expression, MCP-1, RANTES.
\end{abstract}




\section{INTRODUCTION}

Cells, proteins and inflammatory responses play a fundamental role in the development and advancement of atherosclerosis (1). This chronic inflammatory condition occurs in the artery walls and involves both the innate and acquired immune systems (2). According to Ross, atherosclerotic lesions mainly consist of macrophages and T-lymphocytes and involve particularly specialized cellular and molecular responses to be explained merely by atherosclerosis being an inflammatory condition (3). Atherosclerosis develops as soon as arterial inflammation starts, the endothelium gets activated, and preinflammatory proteins such as chemokines are synthesized, leading to a significant increase in the expression and the emergence of cellular adhesion molecules (4). Chemokines are a large family of secreted proteins with a small molecular weight that play a pivotal role in various physiological and pathological processes, such as hematopoiesis, angiogenesis, inflammation, atherosclerosis, infection and immune system diseases $(5,6)$. In terms of function, chemokines are divided into two groups: inflammatory chemokines and constitutively expressed chemokines. The former plays a significant role in the migration of leukocytes to the inflammation site and are involved in the innate immune responses by migrating neutrophils, monocytes/macrophages, dendrites and natural killer cells (7). Studies show that CCL2 and CCL5 are actually the main indices of inflammation development. Monocyte chemoattractive protein 1 (MCP-1), also known as CCL2, is a chemokine that attracts monocytes to the inflammation site in the sub-endothelial space of the arteries. These monocytes are capable of differentiation into macrophages and foam cells by removing OX-LDL, hence playing an important part in the pathogenesis of atherosclerosis (8). Studies show that there is a direct relationship between MCP-1 plasma level and common atherosclerosis risk factors such as hs-C-reactive protein (hs-CRP), plasma fibrinogen and intima media thickness of the carotid artery (9).

CCL5 (RANTES) is a CC chemokine, which is mainly released from T-cells and plaques and stimulates the migration of monocytes, macrophages and T-cells (10). These chemokines are trivially found in the healthy heart, but the expression rises in heart failureassociated hypertrophy. Therefore, this chemokine has been recently introduced as an indicator of heart failure, cancer, inflammation and tissue damage (10).

Physical exercise is known as a major preventer of cardiovascular diseases; however, the relationship between physical exercise and changes in CCL2 and CCL5 expression has not been determined yet. A few studies have dealt with the effect of physical exercise on the expression of these inflammation indicators in patients with heart disease. For example, Billebeau et al. reported that 40 sessions of endurance exercise reduce plasma biomarkers in patients with chronic heart failure (11). A large number of studies have also been carried out on different physical exercises and their outcome within a rehabilitation program. While exercise programs for coronary artery bypass graft $(\mathrm{CABG})$ surgery patients have been mainly focused on endurance exercises, such as aerobic training (12), increasing evidence show that resistance exercise can be more effective in patients if accompanied by aerobic exercises. Such trainings can be applied as a complementary treatment or even as a treatment replacement for patients who are unable to perform aerobic exercises (13). There have also been reports of a decline in CABG patients' muscle mass, which is responsible for decrease in the muscle power, functional capacity, change in body composition and reduced quality of life (14). In this regard, Moosavi et al. investigated the effect of combined training on $A B C G 1$ gene expression in mononuclear cells after $\mathrm{CABG}$ in middle-aged men. They concluded that combined training, as a part of the cardiac rehabilitation process, seems to augment the process of reverse cholesterol transfer by affecting the expression of the $A B C G 1$ gene (15). Our knowledge of chemokines and changes in their expression as a predictor of heart failure is limited and unattended to. In addition, the effect of physical exercise on patients with cardiovascular disease is not determined yet. Therefore, the present study aimed to evaluate effects of eight weeks of cardiac rehabilitation training on expression of CCL2 and CCL5 in peripheral blood mononuclear cells (PBMC) of middle-aged 
men who had undergone CABG.

\section{MATERIALS AND METHODS}

Forty-five participants were selected from the Javad-Al-Aeme hospital and randomly divided into three groups: aerobic exercise $(n=15)$, combined exercise $(n=15)$ and control $(n=15)$. Inclusion criteria were age range of 40-60 years, willingness to participate in the study, cognitive health, normal vision and hearing, blood pressure of <160/100 $\mathrm{mmHg}$, no history of acute or advanced diseases that could limit exercise ability and inability to use auxiliary devices for walking such as cane and walker. Exclusion criteria included use of medications, occurrence of ventricular arrhythmias, ST elevation or fall during training sessions, respiratory disturbance during rehab and unstable angina. The study was approved by the ethics committee of Islamic Azad University of Neyshabour, Iran (code:IR.IAU.NEYSHABUR.1396,13 ). The subjects in the aerobic and combined exercise groups participated in an eight-week training program based on the recommendations of the American College of Sport Medicine (16). Table 1 presents biometrics and some characteristics of the subjects. One week before the first exercise session, the subjects attended an introductory session to become familiarized with the trainings. The rehabilitation program was carried out three sessions per week for eight weeks. Aerobic training included walking on a treadmill for 20-30 minutes, cycling on a fixed bike (10-12 minutes) using the bicycle's ergometer (10 minutes). The subjects warmed-up at the beginning and cooled down at the end of each session with stretching exercises. The trainings began at moderate intensity ( $60 \%$ of maximum heart rate) (17), but the duration and intensity of the trainings increased gradually according to the subjects capacity, so that in the final maximum heart rate. The exercise intensity was assessed using the Borg scale $(18,19)$.

The resistance training program included three sets of physioball squat, shoulder flexion, hip flexion, shoulder abduction, hip abduction, elbow flexion, plantar flexion and ankle dorsiflexion with 8-15 repetitions.

The activities were initially performed with eight repetitions using a weak thera-band (yellow). Then, two repetitions were added to each activity every session until reaching 15 repetitions. The gradual increase of repetitions continued after increasing the strength of the thera-band (pink) (20).

Blood samples $(10 \mathrm{ml})$ were taken after 10-12 hours of fasting, one day before the first training session and 48 hours after the last training session. RNA was extracted using a commercial kit (Qiagen, Germany). Complementary DNA (cDNA) was synthesized using a cDNA synthesis kit (QuantiTect Reverse Transcription Kit cDNA synthesis, Qiagen, Germany) according to the manufacturer's instructions. Real-time quantitative PCR was performed using the Quanti Fast SYBR Green PCR Kit (Qiagen, $\mathrm{GmbH}$, Germany). PCR reaction solution (10 $\mu 1)$ contained $1 \mu \mathrm{l}$ of single-strand cDNA, $5 \mu \mathrm{l}$ of master mix, $1 \mu 1$ of each primer and $2 \mu l$ of RNase- free water. Expected fragment size and oligonucleotide primer sequences for CCL2, CCL5 (21) and $\beta$-actin genes (22) are listed in table 2.

PCR was carried out in a Bio-Rad thermal cycler (USA). PCR products were subjected to session, the intensity was increased to $80 \%$ of electrophoresis on $1.5 \%$ agarose gel. Melting curve analysis and a threshold cycle comparison method was applied to measure the number of target and reference genes (23). Data were analyzed with SPSS 16.0 using oneway ANOVA and the Tukey's post hoc test.

\section{RESULTS}

One-way ANOVA showed a significant difference in the relative expression of CCL2 gene in PBMN cells between the control group, the aerobic exercise group and the combined exercise group $(\mathrm{P}=0.011, \mathrm{~F}=5.37)$. Moreover, there was a significant difference between the control group and the aerobic exercise group $(\mathrm{P}=0.041)$ and between the control group and the combined exercise group $(\mathrm{P}=0.012)$ in terms of $C C L 2$ gene expression (Table 3). Based on the results of one-way ANOVA, there was no significant difference in the expression of CCL5 between the study groups $(\mathrm{P}=0.903, \mathrm{~F}=0.102)$. 
Table 1. Biometrics and some characteristics of the subjects

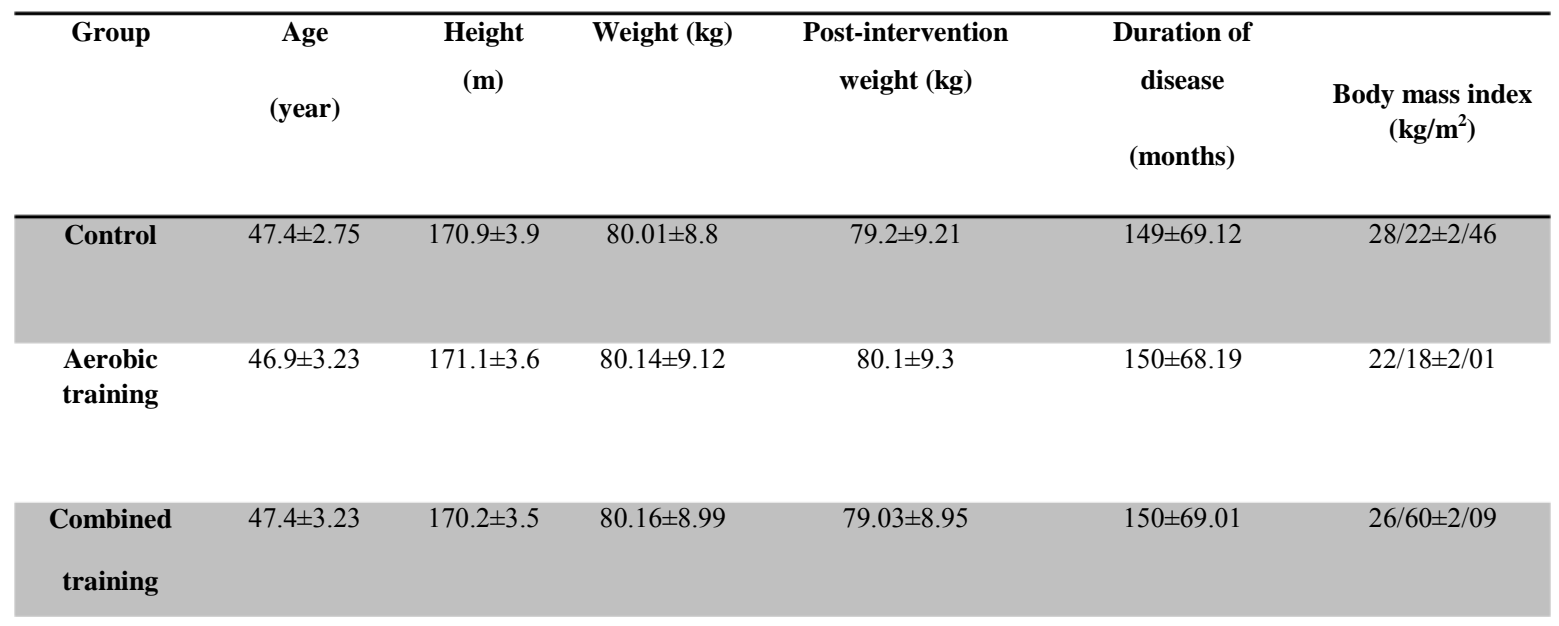

Table 2. Oligonucleotide sequence of primers

\begin{tabular}{lcc}
\hline Primer sequence & Type & Gene \\
\hline 5-GTCTCCCACCACCATCTT-3 & Forward & CCL2, CCL5 \\
\hline 5-TCTGTCTCTGAGTGTAGCCTTAGC-3 & Backward \\
TCCCTGGAGAAGAGCTACG & Forward & $\beta-A c t i n$ \\
GTAGTTTCGTGGATGCCACA & Backward
\end{tabular}

Table 3.One-way ANOVA and Tukey test results for each group

\begin{tabular}{|c|c|c|c|c|c|c|c|c|}
\hline \multirow[t]{2}{*}{ Variable } & \multirow[t]{2}{*}{ Group } & \multirow[t]{2}{*}{ Pre-test } & \multirow[t]{2}{*}{ Post-test } & \multicolumn{2}{|c|}{$\begin{array}{l}\text { Kolmogorov- } \\
\text { Smirnov test }\end{array}$} & \multicolumn{2}{|c|}{ ANOVA } & \multirow[t]{2}{*}{ Tukey's test } \\
\hline & & & & $\bar{Z}$ & Sig. & $\mathrm{F}$. & Sig. & \\
\hline \multirow{5}{*}{$\begin{array}{c}\text { CCL2 } \\
(\mathrm{pg} / \mathrm{ml})\end{array}$} & & & & & & $5 / 370$ & ${ }^{\circ o} 0.011$ & \\
\hline & Control & $1.000 \pm 0.000$ & $* * 1.0 \pm 19.33$ & $0 / 842$ & 0.477 & & & $* * 0.041$ \\
\hline & & & & & & & & $* * 0.012$ \\
\hline & Aerobic & $1.000 \pm 0.000$ & $* * 0.0 \pm 67.44$ & 0.669 & 0.761 & & & \\
\hline & Combined & $1.000 \pm 0.000$ & $* * 0.0 \pm 61.47$ & 0.660 & 0.777 & & & \\
\hline \multirow{4}{*}{$\begin{array}{c}\text { CCL5 } \\
(\mathrm{pg} / \mathrm{ml})\end{array}$} & & & & & & 0.102 & 0.903 & 0.904 \\
\hline & Control & $1.000 \pm 0.000$ & $0.82 \pm 80 / 15$ & 0.830 & 0.496 & & & 0.936 \\
\hline & Aerobic & $1.000 \pm 0.000$ & $0.70 \pm 87.80$ & 0.346 & 1.000 & & & \\
\hline & Combined & $1.000 \pm 0.000$ & $0 / 34 \pm 86.87$ & 0.552 & 0.921 & & & \\
\hline
\end{tabular}

** Significant difference between control group and the exercise groups.

${ }^{\circ}$ Significant difference between the aerobic and the combined exercise groups. 


\section{DISCUSSION}

We observed a significant decrease in the expression of CCL2 in CABG patients after eight weeks of aerobic and combined exercise rehabilitation. However, we found no significant difference between aerobic and combined exercises in this regard. It is pointed out here that cardiac rehabilitation is so far the first therapeutic intervention that results in a decrease in expression of genes involved in the development of atherosclerosis.These findings are in accordance with results of most previous studies (24-27) but inconsistent with results of Shi et al. (28) and Van Wijk (29). In the study of Wilmore, endurance exercise reduced MCP1 and IL-8 in the circulatory system of patients who were susceptible to coronary events. In the study of Trøseid et al., eight weeks of combined endurance and resistance exercise significantly decreased plasma level of MCP-1 and IL-8 in patients with metabolic syndrome. In a review study on the relationship between MCP-1 polymorphism and coronary artery disease based on ethnicity, Pan et al. found that MCP-1A2518G (genotype AG+GG) is a risk factor for coronary artery disease. In another study, high-intensity interval training reduced plasma level of MCP-1 in the visceral and subcutaneous adipose tissue. Inconsistent with these results, Van Wijk et al. reported no relationship between CCL2 gene promoter polymorphism and coronary artery disease. In a similar study by Shi et al., there was no significant relationship observed between A2518G polymorphism of MCP-1 gene and acute coronary syndrome in a Chinese population. There is a significant direct relationship between the plasma level of MCP1 and common risk factors of atherosclerosis such as plasma fibrinogen and hs-CRP and intima media thickness of carotid artery (29).

Findings of the present study showed that eight weeks of rehabilitation slightly decreased CCL5 expression in CABG patients. These finding are in accordance with those of Baturcam et al. (30) and Versteylen et al. (31) but inconsistent with findings of Liu et al. (32).Baturcam et al. studied the effects of physical exercise on expression of CCL5 and its receptor in the adipose tissue of obese people. They found a direct association between CCL5 and CCR5 expression in the adipose tissue and the level of IL-6 and TNF-a.
Therefore, exercise may be beneficial for reducing the deteriorative effects of obesity through CCL5 signaling in the adipose tissue (30). In the study of Versteylen et al., serum level of CCL18 was related to coronary artery disease and CCL5 was separately related to coronary artery obstruction and initiating heart disease (31). Kraaijeveld et al. concluded that high circulating levels of CCL5 might be a marker for unstable angina (33). In contrast, lower serum CCL5 level was found to be associated with coronary heart disease (34). A rise in inflammatory indices may indicate development of atherosclerosis, suggesting that even after $\mathrm{CABG}$, patients may be still susceptible to cardiovascular disease (35).

A few studies have investigated the effects of cardiovascular rehabilitation on the inflammatory indices after open heart surgery. In a study by El Missiri and Taher on 80 patients with acute myocardial infarction or acute coronary syndrome, a rehabilitation program significantly reduced hs-CRP in patients with ischemic heart disease, lessened the number of chain smokers and decreased body mass index (36). Silva et al. studied the effects of inflammatory biomarkers on the effectiveness of physical exercise in patients with heart failure, and found that preinflammation and pre-fibrosis biomarkers have a differential effect on functional capacity during physical activity (37).

Eight weeks of aerobic resistance training significantly improved the biomechanical function of cardiac muscles in myocardial infarction and CABG patients (38). Physical activity directly influences the cardiovascular system by increasing blood and plasma volume, decreasing blood viscosity, increasing stroke volume and $\mathrm{VO}_{2 \max }$. It is recommended to conduct future studies on the effect of different training protocols on both traditional and novel indices of atherosclerosis in people of different age and physical conditions.

\section{CONCLUSION}

Based on the results, the eight-week cardiac rehabilitation training can significantly decrease expression of CCL2 in post-CABG patients. Therefore, this type of exercise could be recommended for prevention of coronary artery occlusion after CABG.

\section{ACKNOWLEDGEMENTS}

We would like to express our gratitude to Dr. Alavi for guiding us throughout this research. 


\section{CONFLICT OF INTEREST}

The authors declare that there is no conflict of interest.

\section{REFERENCES}

1.Zakynthinos E, Pappa N. Inflammatory biomarkers in coronary artery disease. J Cardiol. 2009;53(3):317-33. [DOI:10.1016/j.jjcc.2008.12.007] [PubMed] [Google Scholar]

2. Tedgui A, Mallat Z. Cytokines in atherosclerosis: pathogenic and regulatory pathways. Physiol Rev. 2006; 86: 515-81. [DOI:10.1152/physrev.00024.2005] [PubMed] [Google Scholar] 3. Ross R. Atherosclerosis--an inflammatory disease. N Engl J Med. 1999; 340(2): $115-26$. [DOI:10.1056/NEJM199901143400207] [PubMed] [Google Scholar]

4. Biasucci LM, Vitelli A, Liuzzo G, Altamura S, Caligiuri G, Monaco C, et al. Elevated levels of interleukin-6 in unstable angina. Circulation. 1996;94(5):874-7. [DOI:10.1161/01.CIR.94.5.874] [PubMed] [Google Scholar]

5. Baggiolini M, Dewald B, Moser B. Human chemokines: An update. Annu Rev Immunol. 1997;15:675-705. [DOI:10.1146/annurev.immunol.15.1.675] [PubMed] [Google Scholar]

6. Gerard C, Rollins BJ. Chemokines and disease. Nat Immunol. 2001;2(2):108-15. [DOI:10.1038/84209]

7. Le Y, Zhou Y, Iribarren P, Ming-Wang J. Chemokines and chemokine receptors: Their manifold roles in homeostasis and disease. Cell Mol Immunol. 2004;1(2):95-104. [PubMed] [Google Scholar]

8. Panee J. Monocyte chemoattractant protein 1 (MCP-1) in obesity and diabetes. Cytokine Oct. 2012;60(1):1-12. [DOI:10.1016/j.cyto.2012.06.018] [PubMed] [Google Scholar]

9. Lin J, Kakkar V, Lu X. Impact of MCP-1 in atherosclerosis. Curr Pharm Des. 2014;20(28):4580-8. [DOI:10.2174/1381612820666140522115801] [PubMed] [Google Scholar]

10. Moogooei M, Hasanshahi G, Jafarzadeh A, Khoramdelazad H, Moogooei M, Fatahpour S. Distinct Pattern of CC Chemokine 2 and 5 in Post-Transurethral Resection of Bladder Cancer Journal of Ilam University of Medical Sciences. 2015;24(1):144-53.(persian) [View at Publisher] [DOI:10.18869/acadpub.sjimu.24.1.144] [Google Scholar]

11. Billebeau G, Vodovar N, Sadoune M, Launay JM, Beauvais $\mathrm{F}$, Cohen-Solal A. Effects of acardiac rehabilitation programme on plasma cardiac biomarkers in patients with chronic heartfailure. European Journal of Preventive Cardiology. 2017;24(8):808-17. [DOI:10.1177/2047487317705488] [PubMed] [Google Scholar]

12. Passino C, Severino S, Poletti R, Piepoli MF, Mammini C, Clerico A, et al. Aerobic training decreases B-type natriuretic peptide expression and adrenergic activation in patients with heart failure. J Am Cardiol. 2006;47(9):1835-9. [DOI:10.1016/j.jacc.2005.12.050] [PubMed] [Google Scholar]

13. Gaeini A, Sattarifard S, CafiZadeh S, Nejatian M. The comparison of eight weeks of combined and aerobic training onfunctional capacity, body composition and strength in postcoronary artery bypass graft cardiac patients. Cardiovascular Nursing Journal. 2013;2(1):24-41.(persian) [View at Publisher]

14. Oliveira JL, Galvao CM, Rocha SM. Resistance exercises for health promotion in coronary patients: Evidence of benefits and risks. Int J Evid Based Healthc. 2008; 6(4): 431-9. [DOI:10.1097/01258363-200812000-00005]

15. Feyollah Zadeh Moosavi R, Rashidlamir A, Khajei R, Hejazi $\mathrm{M}$. The effect of combined training on ABCG1 gene expression in mononuclear cells after coronary artery bypass surgery in middle aged men.J Neyshabur Univ Med Sci, autumn, 2019;7(3):49-62. [View at Publisher]

16. American College of Sports Medicine. ACSM's Guidelines for Exercise Testing and Prescription. 6, editor. Baltimore: Md: Lippincott Williams \& Wilkins; 2000.
17. Adams BJ, Carr JG, Ozonoff A, Lauer MS, Balady GJ. Effect of exercise training in supervised cardiac rehabilitation programs on prognostic variables from The exercise tolerance $\begin{array}{llll}\text { test. AM j cardiol. 2008;101(10):1403-7. } & \text {. }\end{array}$ [DOI:10.1016/j.amjcard.2008.01.016] [PubMed] [Google Scholar]

18. Choo J, Burke LE, Pyo-Hong K. Improved quality of life with cardiac rehabilitation for post myocardial infarction patients in Korea. Eur J CardiovascNurs. 2007;6(3):166-71. [DOI:10.1016/J.EJCNURSE.2006.07.004] [PubMed] [Google Scholar]

19. Siavoshi S, Roshandel M, Zareiyan A, Ettefagh L. The effect of cardiac rehabilitation care plan on the quality of life in patients undergoing coronary artery bypass graft surgery. Cardiovascular Nursing Journal. 2012;1(2):38-46.(persian) [View at Publisher] [Google Scholar]

20. Pollock ML, Franklin BA, Balady GJ, Chaitman BL, Fleg JL, Fletcher B, et al. AHA Science Advisory. Resistance exercise in individuals with and without cardiovascular disease: benefits, rationale, safety, and prescription an advisory from the committee on exercise, rehabilitation, and prevention, council on clinical cardiology, AmericanHeart Association. Circulation2000;101(7):828-33.

[DOI:10.1161/01.CIR.101.7.828] [PubMed] [Google Scholar]

21. Reisi J, Rajabi H, Ghaedi K, Marandi SM, Asadysamani Z, Kazeminasab F. Effect ofeight weeks' resistance training on plasma irisin protein level and muscle FNDC5 and adipose tissue UCP1 genes expression in male rats. Exercise phisiology. 2015;7(28):117-30. [DOI:10.5812/asjsm.35205] [ [Google Scholar]

22. Ghanbari-Niaki A, Ghanbari-Abarghooi S, Rahbarizadeh F, Zare-Kookandeh N, Gholizadeh M, Roudbari F, et al. Heart ABCA1 and PPAR- $\alpha$ Genes Expression Responses in Male rats: Effects of High Intensity Treadmill Running Training and Aqueous Extraction of Black Crataegus-Pentaegyna. Res Cardiovasc Med. 2013;1(5):153-9.(persian) [DOI:10.5812/cardiovascmed.13892] [PubMed] [Google Scholar]

23. Livak KJ, Schmittgen TD. Analysis of relative gene expression data using real-time quantitative PCR and the 2(Delta DeltaC(T)) Method. Methods. 2001;25(4):402-8. [DOI:10.1006/meth.2001.1262] [PubMed] [Google Scholar]

24. Wilmore JH. Aerobic Exercise and Endurance, Improving Fitness for Health Benefits. The physician and sports medicine. 2003;31(5):356-9. [DOI:10.3810/psm.2003.05.367] [PubMed] [Google Scholar]

25. Trøseid M, Lappega ${ }^{\circ}$ rd KT, Claudi T, Damås JK, Mørkrid $\mathrm{L}$, Brendberg R, et al. Exercise reduces plasma levels of the chemokinesMCP-1 and IL-8 in subjects with the metabolicsyndrome. European Heart Journal. 2004;25(4):34955. [DOI:10.1016/j.ehj.2003.12.006] [PubMed] [Google Scholar]

26. Pan J, Gao C. Association between MCP-1 A2518G polymorphism and coronary artery disease risk: evidence from 21 case-control studies. Int J Clin Exp Med. 2016;9(7):1408795. [Google Scholar]

27. Kazemi A. Effect of high intensity interval training on visceral and subcutaneous levels of MCP-1 and plasma insulin and glucose in male rats. Razi journal of Medical Sciences. 2017;23(152):29-37.(persian) [Google Scholar]

28. Shi G, He G, Cai G, Qi CP, Gao L, Shen D, et al. Association between MCP-1 gene polymorphism and acute coronary syndrome in a Hanethnic Chinese cohort. world $\mathrm{J}$ Emerg Med. 2013;4(1):38-44. [DOI:10.5847/wjem.j.issn.19208642.2013.01.007] [Google Scholar]

29. Van-Wijk DF, Van-Leuven SI, Sandhu MS, Tanck MW, Hutten BA, Wareham NJ, et al. Chemokine Ligand 2 Genetic Variants, serum MCP-1 Levels and the Risk of Coronary Artery Disease. ArteriosclerThrombVasc Biol July. 2010;30(7):1460-6. [DOI:10.1161/ATVBAHA.110.205526] [PubMed] [Google Scholar] 
30. Baturcam E, Abubaker J, Tiss A, Abu-Farha M, Khadir A, Al-Ghimlas F, et al. Physical Exercise Reduces the Expression of RANTES and its CCR5 Receptor in the Adipose Tissue of Obese Humans. Mediatirs of inflammation. 2014;2014:1-13. [DOI:10.1155/2014/627150] [PubMed] [Google Scholar]

31. Versteylen MO, Manca M, Joosen A, Schmidt DE, Das M, Hofstra L, et al. CC chemokine ligands in patients presenting with stable chest pain: association with atherosclerosis and future cardiovascular events. Neth Heart J. 2016;24(12):722-9. [DOI:10.1007/s12471-016-0884-9] [PubMed] [Google Scholar]

32. Liu J, Jia YJ, Li XL, Xu RX, Zhu CG, Guo YL, et al. RANTES Gene G-403A Polymorphism and Coronary Artery Disease: A MetaAnalysis of Observational Studies. PLoS ONE. 2012;7(10). [DOI:10.1371/journal.pone.0047211] [PubMed] [Google Scholar]

33. Kraaijeveld AO, de Jager SCA, de Jager WJ, Prakken BJ, McColl SR, Haspels I, et al. CC chemokine Ligand-5 (ccl5/RANTES) and CC chemokine ligand-18() are specific markers of refractory unstable angina pectoris and are transiently raised during severe ischemic symptoms. Circulation. 2007; 116(17):1931-1941. [DOI:10.1161/CIRCULATIONAHA.107.706986] [PubMed] [Google Scholar]

34. Rothenbacher D, Müller-Scholze S, Herder Ch, Koenig W, Kolb H. Differential expression of chemokines, risk of stable coronary heart disease, and correlation with established cardiovascular risk markers. Arteriosclerosis, Thrombosis,and Vascular Biology.2006;26(1):194-199. [DOI:10.1161/01.ATV.0000191633.52585.14] [ [Google Scholar]
35. Blake GI, Ridker PM. Novel clinical marker of vascular wall inflammation. Circulation res. 2001;89(9):763-71. [DOI:10.1161/hh2101.099270] [PubMed] [Google Scholar]

36. ElMissiri A, Taher MA. Effect of Phase 2 Cardiac Rehabilitation Program on High-SensitivityCReactiveProteinLevels in Post-Percutaneous Coronary Intervention Patients. J Cardiovasc Res. 2016;5(1):1-6. [Google Scholar]

37. Fernandes-Silva MM, Guimarães GV, Rigaud VO, LofranoAlves MS, Castro RE, de-Barros-Cruz LG, et al. Inflammatory biomarkers and effect of exercise on functional capacity in patientswith heart failure: Insights from a randomized clinical trial. European journal of preventivecardiology. 2017;24(8):808-17. [DOI:10.1177/2047487317690458] [Google $\underline{\text { Scholar] }}$

38. Razaghi A, Sadeghi H, Johari Moghadam A, Azma K, Motamedi P. The effect of exercise-based cardiac rehabilitation in two ways aerobic and aerobic-resistance exercises on the biomechanical function of cardiac patients (MI, PCI, and $C A B G$ ). Razi J Med Sci. 2020;26(12):138-148. [View at Publisher] [Google Scholar]

\section{How to Cite:}

Alavizadeh NS, Rashidlamir A M, Hejazi S. [Effect of Eight Weeks of Aerobic and Aerobic-Resistance Trainings after Coronary Artery Bypass Grafting on Expression of CCL2 and CCL5 in Middle-Aged Men].mljgoums.2021;15(1):19.25DOI: $10.29252 / \mathrm{mlj} .15 .1 .19$ 